\title{
Introduction \\ Cultural history of medical regulations
}

\author{
Patrice Bourdelais
}

7 his issue is mainly focused on cultural and political changes in public health regulations since the end of the nineteenth century in several

European countries. The most important task for historians, except of improving knowledge, is to analyse conditions in the past and to explain how and why they have changed, leading to the world we know today. One part consists of verifying the facts and events as precisely as possible. Another part is to analyse the situation and the factors responsible for evolution and changes. This is linked to general questions asked within social sciences, and to how historians use theoretical and methodological tools developed by other scientific disciplines. The set of articles presented here provide a wide range of examples of the historians' practices today and of the current state of research. As far as medical and public health history is concerned, the medical profession, the states, public institutions, and the population are traditionally seen as the main actors. But since the end of the nineteenth century, biochemical and pharmaceutical companies, media and international institutions have been more and more present.

Nevertheless, it would be naïve to think that, because of the numerous and extensive programmes implemented at that time, the importance of diet, environment, housing and behaviour as factors of personal and collective health was not acknowledged before the First World War, The Hippocratic tradition, rediscovered in Europe during the second half of the eighteenth century, emphasised the role of climate, local environment, diet and habits. The medical doctors paid attention to the public health during the nineteenth century. Hygienists tried to show the links between the mortality level and the gradient of wealth with Louis René Villermé as the foremost protagonist. At the end of that century, even after the discovery of the tuberculosis bacillus by Robert Koch, the representatives of the socialist movement argued that living conditions and the exhaustion of work were the most important factors for contagion, more than spitting and alcoholism, as claimed by the medical faculties. 
The first dispensaries appeared at the end of the nineteenth century and just before the First World War. However, no coherent and broad programme to fight diseases and promote living conditions of the poor was implemented. The major reason for this lack of response is that the liberal ideology led governments to avoid public expenses. This reluctance explains why the role of philanthropy was so important.

The First World War changed the world of public health politics. The loss of millions of young men, the discovery of extended vulnerability to TB during the war, and the Communist revolution in Russia, led to a redefinition of priorities. The population had to be more efficiently protected against infectious diseases, leading to the implementation of extensive interventions to fight tuberculosis, venereal diseases and social health problems such as prostitution and alcoholism. It was argued that the poor population must be assisted with new lodging and housing programmes, making it less vulnerable to diseases and less susceptible to communist ideals. Hence, the political culture became more positive to public health regulations.

A first set of articles in this volume deals mainly with the ways in which medicine and public health has been more and more seen in the light of a social dimension. The example of projects lead by the new international institution, the League of Nations Health Organization (LNHO) during the interwar period are in line with ideas emerging during the nineteenth century even if, for instance, the role of nutrition had by then been further supported by science. The importance of the international institutions was to provide contacts and collaboration, especially during the period with huge political tensions between the states. What had not been possible to organize before the Great War was suddenly put on the agenda and implemented. Comparative surveys were organised by the LNHO from a social and contextualised approach as shown in Iris Borowy's article. To some extent this approach fitted well for authoritarian regimes, such as the Soviet Union Italy and Germany but some aspects were also appreciated by democratic states.

In each state the social dimension of public health policies was developed, theoretically and through the implementation of institutions or practices. Esteban Rodriguez Ocaña analyses the change from the use of biological terms to describe society to the introduction of social concepts within Spanish medicine, including the evolution of social medicine as a branch of public health. He describes how 'social diseases' were defined, showing that it "became an outstanding rhetorical device to attract public interest, and consequently money and jobs which produce new specialties through the timely health campaigns". The main priority areas for policy were infant mortality and tuberculosis, serving as models for other diseases. These campaigns also helped medical professionals to reinforce their monopoly, to strengthen the argu- 
ments for political interventions by compensating for the bad conditions of work and life of the large majority of the population by massive programmes of prevention and care.

Another example from the inter-war period is the article about the First Czechoslovak Republic (1918-1938) by Hana Masova. The new political authorities tried to improve the situation after the disaster of the war by medical and social interventions and by creating new institutions in which preventive and curative measures could be complementary. Dispensaries were developed and the American Red Cross and Rockefeller Foundation brought money and organizational aid. The paper analyses how the district of Vršovice-Praha XIII used the newest available techniques in social hygiene and healthcare when coordinating social work and health service.

The circulation of knowledge on social hygiene and medicine was also found in the general media. Linked to the new public health institutions and to the new agenda more oriented to social factors, a large number of "educational" movies were produced in all European countries during the interwar period, Enrique Perdiguero, Rosa Ballester and Ramon Castejon present the case of Spain, especially focusing on two movies as examples of health campaigns directed against the high rates of infant mortality. They analyse the forms and the contents of the movies, which emphasize the role of medicine as a solution to the problems addressed, arguing for the importance of traditional values, including the special role of the woman in the family context. Some change in the latter respect is, however, observable during the Spanish political regime of 1928-1936 with less focus on "catholic" values and a less traditional image of the woman, for instance showing her when taking part in sports activities

A large number of this type of movies, devoted to traditional health campaigns, were produced in many European countries between the two World Wars, urging for more comparative research.

The second set of papers is more focused on different regulations in European societies regarding new medications, the fight against TB and venereal diseases, health insurance systems and the prevention against medical quacks and charlatans. Taking the case of the serum against diphtheria and its concomitant production in France and in Germany, Axel Huentelmann compares the ways in which the two states regulated the quality of the products. In Germany, several pharmaceutical companies produced the serum and the sale was controlled by the state, which delegated the oversight to different State institutions such as the Imperial Health Office and the Institute for Serological Research and Serological Survey. In France the story turns around the Pasteur Institute. There was no direct state control over serum production, and after the initial approval of the serum producers, the quality control of the 
serum remained in the hands of the producers themselves. The analysis shows a complex reality with a lot of differences but also similarities between the cases.

It is difficult to speak about state activities in public health without considering the cases of tuberculosis and venereal diseases. Ida Blom compares the regulations of these two diseases in three Scandinavian countries: Norway, Denmark and Sweden. Differences appeared between the countries, in chronology and in the type of constraints imposed to ailing people. Due to different modes of contamination, venereal diseases were less of a threat for the whole society than tuberculosis but controls were obviously stricter for VD than for TB. Moreover, a gender dimension is evident. Women were seen as the main danger and hence the most controlled and prosecuted until recent years. Ida Blom also proposes explanations why the three neighbouring countries did not apply exactly the same policies due to their particular political, cultural and epidemiological histories.

During the interwar period, many European countries organized health insurance systems. Maria Isabel Porras presents results from a comparative study of the implementation of compulsory health insurance systems in France and Spain, two countries with different economic and social structures but very close in terms of medical issues. After the limits set by the policies of the nineteenth century mentioned above, the priority was to provide care for poor people at the turn of the next century, for instance represented by the French law on Free Medical Aid in 1892. But the trade unions of medical doctors were opposed to state intervention, fearing that it might reduce their free practice of medicine. This tension was present in France and in Spain until the Second World War, which delayed the introduction of new public medical insurance systems. Internal French debates were to some extent imported to Spain and adapted. There, the opposition against state involvement ceased after the Civil war by the arrival of the Franco's dictatorship. In France the same resistance was progressively weakened after the 1930 when "assurance social laws" were passed and after the Second Word War the entire system of Sécurité sociale was introduced. Finally the system included a compulsory health insurance which respected the principles of liberal medicine. Today we have learnt that social security systems, which gave access to care for the entire population, also proved to be been beneficent for the economic prosperity of the medical professions.

The complexity of regulations appears clearly in the case of the history of homeopathy in Sweden and the "Pill scandal" in the 1950's analysed by Motzi Eklöf. She shows how the history of homeopathy in Sweden passed through prosperous decades as well as periods of decline. A wide range of factors are listed as reasons for the decline, for instance the fear for all sort of sectarianism 
after the Second World War the increased social legitimacy of the established medical science and the sensitivity of public opinion to "affairs and scandals". Finally, a trial against a homeopathy manufacture to produce just sugar pills, introduced a new strategy of charging lay healers with fraud instead of health quackery, which proved to be a successful weapon for the medical establishment. More generally, this episode addresses questions about the place of alternatives medicines in European societies.

The third set of papers is more oriented towards cultural issues. The links between enlightenment, science, medicine and religion are elaborated in the case of the Catholic Western Germany around 1800 by Walter Bruchhausen. He shows that they were more complex than usually thought. Many university professors in medicine were also be engaged in religion and it was not considered contradictory for them to be positively involved in the Enlightenment movement. For a previously rarely studied period, Sünje Prühlen gives her results from a work in progress regarding wet-nurses in European German speaking regions from the late Middle Ages to the Early Modern Period with examples of different Western European practices.

All the contributors to this volume demonstrate how - even if differences exist between countries - a common pattern was shared in Europe at the end of the nineteenth century and the beginning of the twentieth century, particularly regarding the acceptance of the necessity of the state's involvement in public health regulation. It became evident that, in order to make real and sustained progress, both medical knowledge and social reform had to be included in public health policies.

The last sentence of an important book by the Belgian doctor René Sand, one of the pioneers of social medicine, gives us a taste of the flavour of the global project: "By building a shelter, making clothes, kindling a fire, fashioning implements, or raising dams, primitive man claimed to be the master of his destiny. It behoves his descendants now to banish disease, poverty, ignorance and neglect. Sociological medicine is one of the instruments which will bring us nearer to this goal" ${ }^{1}$.

Patrice Bourdelais is professor and dírecteur d'études at Écoles des Hautes Études en Sciences Sociales (EHESS) in Paris.

1 René Sand, Health and Human Progress. An essay on sociological medicine, London, Kegan Paul, Trench, Trubner and Co., 1935, p. 260. 